\title{
SHARP CHANGES IN THE ORDINARY MODE MICROWAVE EMISSION FROM A STABLE SUNSPOT: MODEL ANALYSIS
}

\author{
D. Bezrukov ${ }^{1,2}$, B. Ryabov ${ }^{1,2}$, N. Peterova ${ }^{3}$, N. Topchilo ${ }^{4}$ \\ ${ }^{1}$ Ventspils International Radio Astronomy Centre, \\ 101 Inzenieru Str., Ventspils, LV-3601, LATVIA \\ ${ }^{2}$ Institute of Astronomy, University of Latvia, \\ 19 Rainis Blvd, Riga, LV-1586, LATVIA \\ ${ }^{3}$ Special Astrophysical Observatory, \\ St. Petersburg Branch, Russian Academy of Sciences, \\ St. Petersburg, 196140, RUSSIA \\ ${ }^{4}$ V.V. Sobolev Astronomical Institute, \\ St. Petersburg State University, \\ 2 Bibliotechnaya Pl., Staryi Peterhoff, \\ St. Petersburg, 198504, RUSSIA
}

\begin{abstract}
In the work, interpretation is given for a microwave source associated with a stable isolated sunspot as a sample to study the sharp changes in ordinary mode microwave emission. The appropriate microwave source of the solar active region NOAA 10325 was observed with the radio telescope RATAN-600 and the Nobeyama Radio Heliograph during March 30 - April 4, 2003. The radio emission brightness in ordinary mode is shown to be depressed below the brightness of the quiet Sun when the sunspot was near the solar disk centre (April 2-3) but sharply increased in the wavelength range $1.76-2.67 \mathrm{~cm}$ at the longitudes $|\theta|>50^{\circ}$.

Microwave radiation by gyroresonance mechanism is analysed in relation to the particular features of the images taken in He I $10830 \AA$ chromospheric line (Chromospheric Helium-I Imaging Photometer) and EUV emission lines (Coronal Diagnostic Spectrometer). We have constructed a new model according to which above the sunspot's surroundings at the levels of gyroresonance emission the atmosphere is as cold as a "sunspot plume" $\left(T \sim 10^{5}-10^{6} \mathrm{~K}, N \sim 10^{9} \mathrm{~cm}^{-3}\right)$. As could be supposed from the He I line intensity, the central part of the sunspot atmosphere contains open magnetic field and rarefied plasma $\left(N \sim 10^{8} \mathrm{~cm}^{-3}, T \sim 10^{5.5}-10^{6} \mathrm{~K}\right)$.
\end{abstract}

\section{INTRODUCTION}

The centimetre emission from sunspot-associated sources is highly polarized at the wavelengths for which the most productive gyroresonance levels $\left(2^{\text {nd }}\right.$ and $\left.3^{\text {rd }}\right)$ are characteristic, with location in the chromosphere-corona transition region. Excessive radio brightness in the extraordinary wave mode (e-mode) in this region is the result of more effective gyroresonance radiation in this mode and a positive temperature gradient along a given ray path $[1,2]$. Almost fully polarized emission from a newly emerged sunspot is reported in [3]. According to these observations, the most productive $2^{\text {nd }}$ and $3^{\text {rd }}$ gyroresonance levels (the latter being the first higher level) penetrate into the transition region. In [4] it is shown that the $1.76 \mathrm{~cm}$ 
source associated with a large sunspot is typically more than $90 \%$ circularly polarized (since there is only the $3^{\text {rd }}$ harmonic radiation when $B_{\max }<3000 \mathrm{G}$ ). The thermal free-free mechanism alone supplies $0.5-16 \%$ of the peak radio brightness at $1.76 \mathrm{~cm}$ over the sunspot-associated source, and therefore the gyroresonance mechanism dominates [4]. A unique source of the kind with deep depression in the ordinary mode (o-mode) radiation at short $\mathrm{cm}$ is described in [5]. The o-mode brightness reported there was below that of the quiet Sun $\left(10^{4} \mathrm{~K}\right)$ at $1.76 \mathrm{~cm}$ during several days when this source was passing the central solar meridian (CSM). At the same time, brightness of the o-mode increased almost to the level of e-mode radiation as the source moved away from the CSM. One more example of deep depression in the o-mode radiation at short $\mathrm{cm}$ wavelengths is presented in this paper (see also review [6] on the microwave depression).

The gyroresonance emission strongly depends on the propagation angle between the magnetic field and the line of sight, which varies while the sunspot is passing the solar disk. If a precisely longitudinal propagation of microwaves through the vertical magnetic field lines occurs in the centre of solar disk, a deep depression could be expected, especially in the o-mode radiation. Gelfreikh and Lubyshev [7] have simulated in detail the depression in the central part of sunspotassociated microwave source as due to the propagation effects. In the case of a stable microwave source, with depression lasting a few days [8], relatively cool plasma persisted in the atmosphere of sunspot umbra. In [6], the radio brightness depression is definitely ascribed to the gyro-levels embedded in the cool plasma of a sunspot plume.

The multichannel microwave observations of the NOAA 10325 with the radiotelescope RATAN-600 enable evaluation of the heights of plasma at the transition region temperatures in relation to the gyro-levels at definite wavelengths. Indications of cool plasma (sunspot plume) above the sunspot under consideration are found in the SOHO Coronal Diagnostic Spectrometer (CDS) data (April 2-3, 2003). The Nobeyama Radio Heliograph (NoRH) allows comparison of the $1.76 \mathrm{~cm}$ depression outline with the EUV images obtained using the CDS. We have employed model simulations to estimate both the factors influencing the radio brightness in o-mode: the propagation of microwaves and the gyroresonance radiation of plasma at low temperatures. The regular variations in the o-mode brightness correlate with the longitudinal position of the sunspot-associated source: the greater the distance from the CSM, the greater the radio brightness in o-mode. It is a characteristic feature not only of the NOAA 10325 but also of the NOAA 10105 stable isolated sunspot [5]. The goal of our study was to construct the model atmosphere of the isolated sunspot NOAA 10325 and propose interpretation of the microwave observations based on this model.

\section{ACTIVE REGION 10325: OBSERVED PROPERTIES}

Within the period from March 28 to April 4, 2003 the active region 10325 was found to consist of a flocculus and a stable sunspot with the area of about 300 millionths of the solar disk and the magnetic field $B>3000 \mathrm{G}$. The sunspot (latitude $\varphi=12 \mathrm{~N}$, CSM passage on April 3, 2003) did not change much as to its area, magnetic field, and flare activity. In $\S 2.1$ we describe the radio data and the observational features of the NOAA 10325 sunspot in view of the sharp changes in 
o-mode microwave emission. The observations of the sunspot in optical and EUV lines are described in $\S 2.2$.

\subsection{Radio data}

From the maps taken with the NoRH (providing the angular resolution of $\left.\sim 10^{\prime \prime}\right)$ in Stokes I and $\mathrm{V}$ we recalculated the right and left circular polarization (r.c.p., R, 1.c.p., L) maps, where two types of the $1.76 \mathrm{~cm}$ radio brightness changes in the o-mode could be seen (Fig. 1).
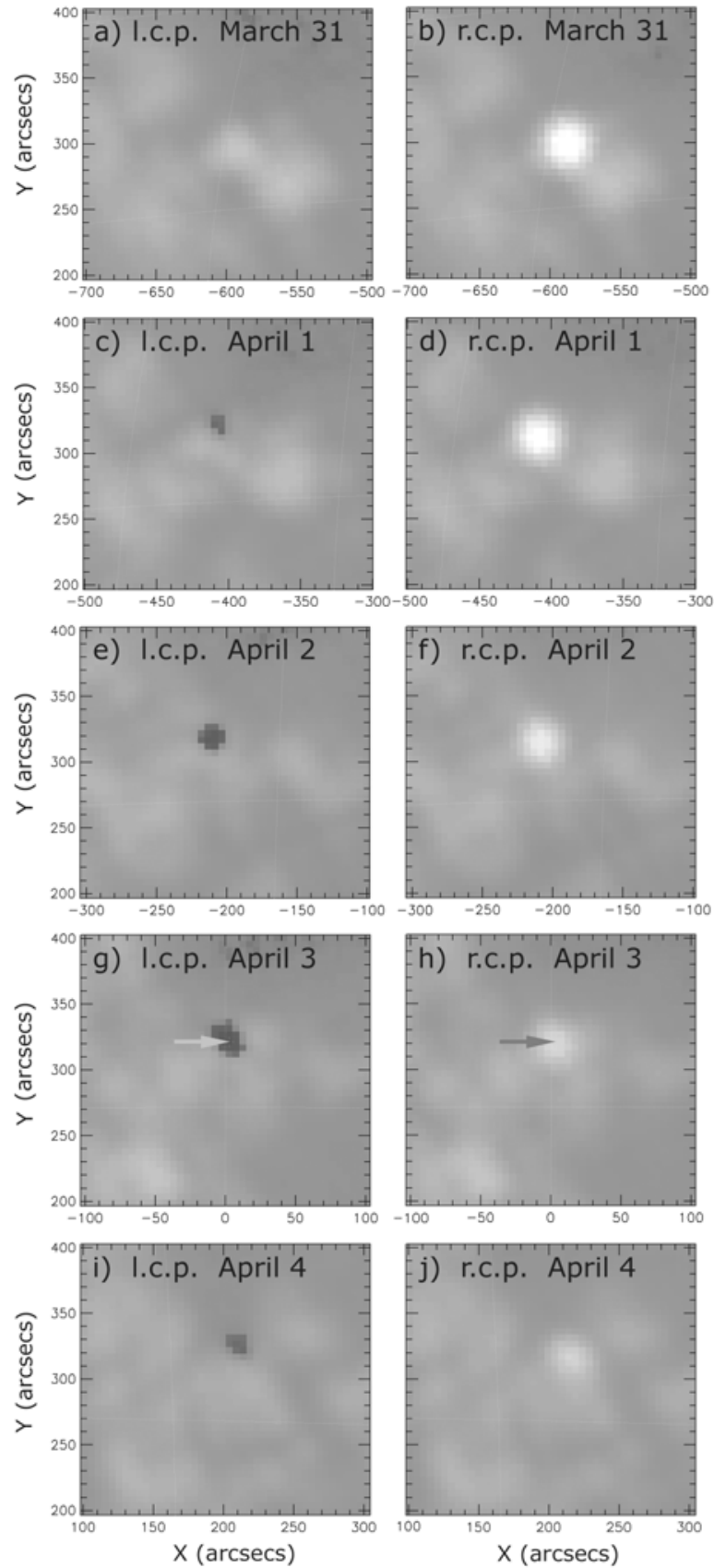

Fig. 1. The 2D radio images of NOAA 10325 sunspot recorded with the NoRH at $1.76 \mathrm{~cm}$ (1 column - in 1.c.p., 2 column - in r.c.p. Position of the minimum brightness in o-mode is marked by arrow in $(g)$ and $(h)$. 
First, a significant decrease in the radio brightness (from $T_{B}=3.7 \cdot 10^{4} \mathrm{~K}$ to $9 \cdot 10^{3} \mathrm{~K}$ ) occurs when the active region 10325 approaches the CSM (April 1, see Fig. 2).

The second type of $1.76 \mathrm{~cm}$ radio brightness changes in the o-mode (Fig. 2) is its significant rise - from $T_{B} \approx 310^{3} \mathrm{~K}$ to $910^{3} \mathrm{~K}$ (April 3-4). The minimum brightness of $3100 \mathrm{~K}$ is for April 3 - the day of the CSM passage. Note that the minimum brightness temperature of $4100 \mathrm{~K}$ in the sunspot umbra is revealed from 5 -min oscillations detected at the wavelength $1.76 \mathrm{~cm}$ [9]. The relevant changes in the circular polarization of the sunspot-associated source are: from $\rho^{V}=76 \%$ to 92\% on April 1, and from $\rho^{V}=91 \%$ to $72 \%$ on April 4 .

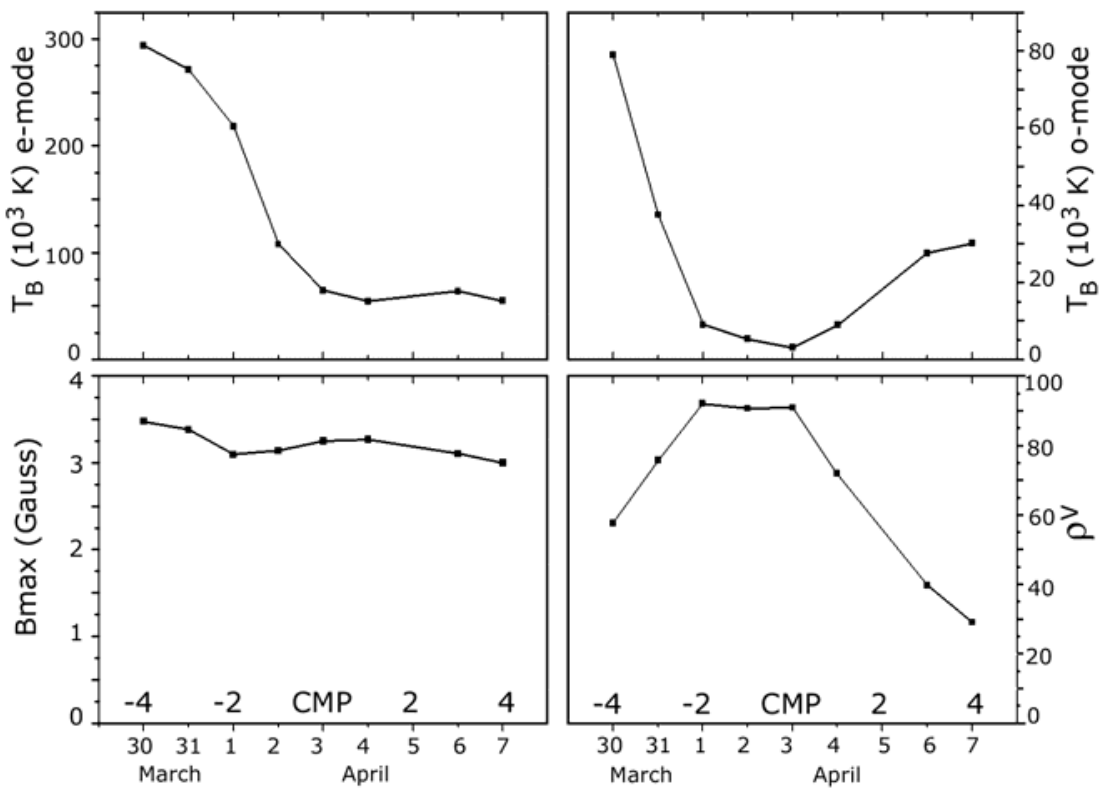

Fig. 2. The day-to-day variations in the sunspot and the related source parameters with regard to the time of CSM passage: radio brightness $T_{B}$ in e- and o-modes together with the degree of circular polarization at $1.76 \mathrm{~cm}(\mathrm{NoRH})$ and the maximum magnetic field $B \max$ (SOHO MDI) (adjusted for the projection effect).

Similarly to the above effects shown in NoRH maps, significant fall and rise of radio brightness in o-mode are observable with the radiotelescope RATAN-600 in the range of 1.83-2.67 cm (horizontal HPBW is 15.5"-22.6") around the time of CSM passage, April 1 and April 4, respectively (Fig. 3). These changes seem to be negligible at the wavelengths $\lambda>2.67 \mathrm{~cm}$. The sharp changes of the radio brightness in the left circular polarization (i.e., in o-mode, on the condition of prevailing radiation in e-mode) are clearly seen despite that the MDI magnetograms and the white light sunspot images do not show significant variations during the radio observations with the RATAN-600 in the period March 30-April 5.

The symmetry of a microwave source in 1D scans (RATAN-600) undergoes some modifications in time and wavelength in both o- and e-mode (Fig. 3). In the $2 \mathrm{D}$ images at $\lambda=1.76 \mathrm{~cm}(\mathrm{NoRH})$ the minimum intensity in o-mode (marked by an arrow in Fig. 1) nearly coincides with the maximum intensity in e-mode. The timeline of the intensity depression in o-mode at short wavelengths $(1.76-2.32 \mathrm{~cm})$ is more or less centred with respect to the time of CSM passage on April 3. Similar symmetry was observed in the case of large isolated sunspot NOAA 10105 [5]. 


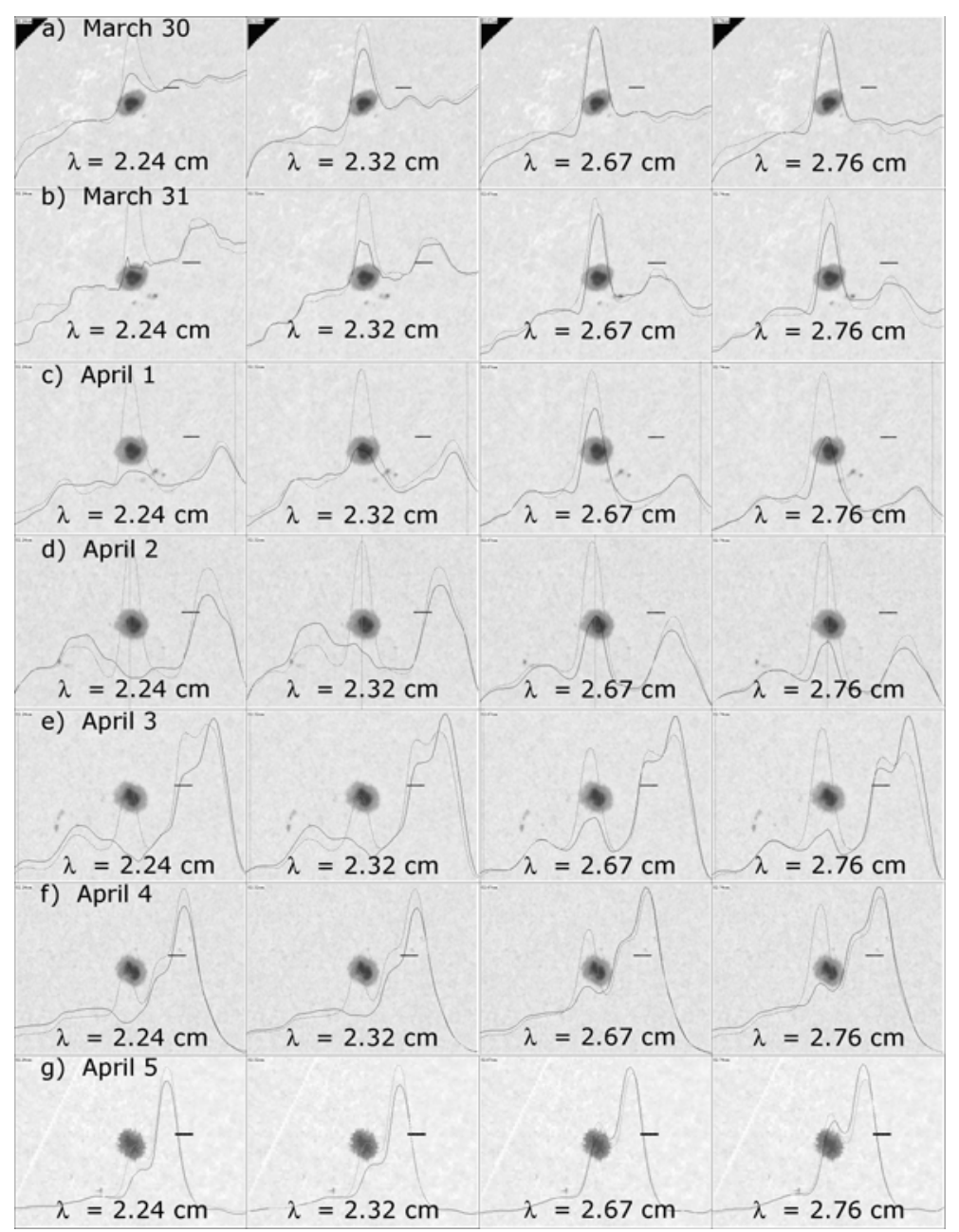

Fig. 3. The 1D radio scans of NOAA 10325 recorded by the RATAN-600 in r.c.p. (e-mode, light curves) and l. c. p. (o-mode, dark curves) at $2.24 \mathrm{~cm}, 2.32 \mathrm{~cm}, 2.67 \mathrm{~cm}$, and $2.76 \mathrm{~cm}$ (columns) on: (a) March 30; (b) March 31; (c) April 1; (d) April 2; (e) April 3; (f) April 4; (g) April 5. White light photos (SOHO) of the active region are superimposed.

It is important to emphasize two significant properties of the sunspotassociated source in the wavelength range $1.76-2.67 \mathrm{~cm}$ :

- unusually low brightness of the source in o-mode (below the level of the quiet Sun at $1.76 \mathrm{~cm}$ ) near the central meridian.

- the radio brightness in o-mode is as high as in e-mode at solar longitudes $|\theta|>50^{\circ}$.

Noteworthy is also the nearly constant size of the microwave source, $\approx 40^{\prime \prime}$, at all the short $\mathrm{cm}$ wavelengths $(2-6 \mathrm{~cm})$.

\subsection{Optical and EUV data}

Search logic had led us from microwave peculiarities inherent in the isolated sunspot-associated source NOAA 10325 to those of the EUV images obtained with the Coronal Diagnostic Spectrometer (CDS) and the image in He I $10830 \AA$ line obtained with the Chromospheric Helium-I Imaging Photometer (CHIP) of the Mauna Loa Solar Observatory (MLSO). 
The active region NOAA 10325 was observed with the SOHO CDS/NIS spectrograph on April 2 and April 3, 2003. In Fig. 4, the CDS/NIS images are coaligned with a contiguous SOHO MDI white light images.

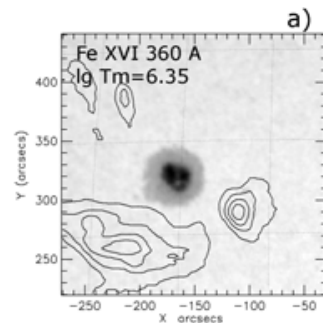

April 2
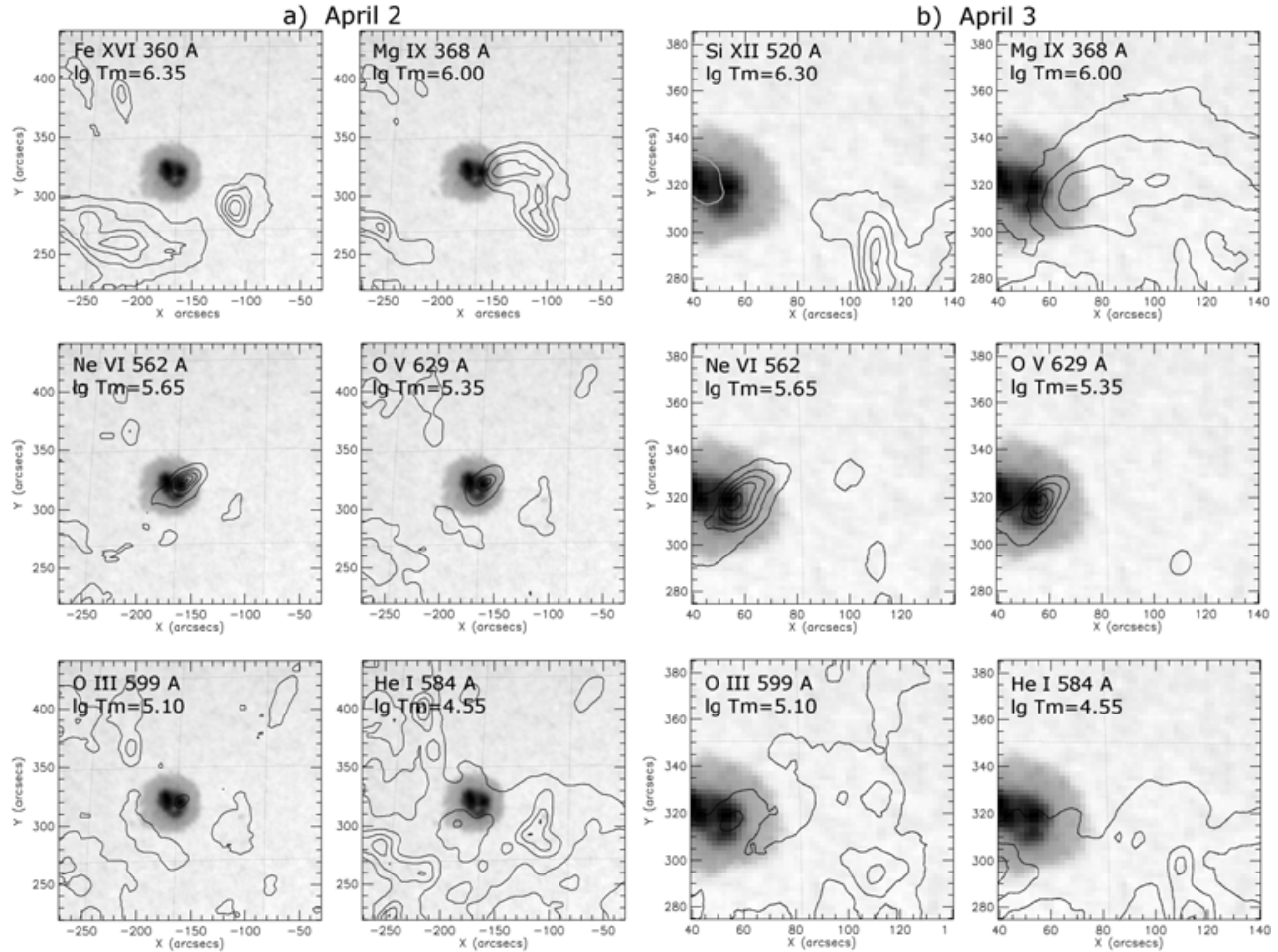

Fig. 4. (a) Images of the sunspot in AR 10325 in EUV emission lines recorded by SOHO CDS/NIS between 07:03 and 7:30 UT (April 2, 2003). The EUV emission lines are: Fe XVI 360 A (ion formation temperature $\left.\log T_{m}=6.35\right), \mathrm{Mg}$ IX $368 \mathrm{~A}$ (6.00), Ne VI $562 \mathrm{~A}$ (5.65), O V 629 A (5.35), O III 599 A (5.10), and He I 584 (4.55). Solar North is at the top and West - to the right. The SOHO MDI white light images are rotated to the position at 7:30 UT. (b) same as (a) but for CDS/NIS observation time 07:00-7:37 UT (April 3, 2003). The EUV emission lines are: Si XII 520 A $\left(\log T_{m}=6.3\right), \mathrm{Mg}$ IX 368 A (6.00), Ne VI 562 A (5.65), O V 629 A (5.35), O III 599 A (5.10) and He I 584 (4.55).

Figure 4 provides evidence that the sunspot umbra is covered by plasma with the ion formation temperature $T_{m}$ in the range $(2.2-4.5) 10^{5} \mathrm{~K}\left(\log T_{m}=5.35-5.65\right)$. The coronal emission of Mg IX line extends to the periphery of the sunspot, whereas Ne VI and O V lines of higher intensity dominate over the area within the outer boundary of the sunspot penumbra. These CDS images, though not precisely calibrated, evidence for a sunspot plume. Instead of the microwave brightness depression in the wavelength range 3.7-6.6 cm (associated with a sunspot plume by Brosius and White [6]), the brightness depression in NOAA 10325 was observed at shorter wavelengths of $1.76-2.67 \mathrm{~cm}$, predominantly in the o-mode. Some authors (see, e.g. $[6,8]$ ) found an apparent correlation between the location of sunspot plume and the magnetic field strength characteristic of gyroresonance emission in the microwave region. In the case of NOAA 10325, the magnetic fields which radiate by the gyroresonance mechanism (predominantly in the e-mode implying highly polarized emission in the wavelength range $1.76-2.67 \mathrm{~cm}$ ), are located to 
the north-east from the sunspot plume (cf. Figs. 4 and $3 e, f$ ). The lower heights of gyro levels for short $\mathrm{cm}$ wavelengths might be the reason for the fully depressed gyroresonance radiation from the sunspot plume over the south-west of the sunspot.

To find dissimilarities among two regions of the sunspot atmosphere (i.e., occupied and not occupied by sunspot plume) we have studied a set of images taken in chromospheric line He I $10830 \AA$ (Fig. 5). This is a chromospheric absorption line (in the general case optically thin) regarded as a tracer of the upper chromosphere and exciting coronal emission. The He I images show weak absorption in the coronal holes, and strong absorption in active regions and $\mathrm{H \alpha}$ filaments [11]. The light area over the sunspot (weakened absorption) in the chromospheric He I line (Fig. 5b) correlates with the location of both the minimum in o-mode (1.c.p., marked by an arrow in Fig. $5 c$ ) and the maximum in e-mode (r.c.p. in Fig. $5 d$ ) at $1.76 \mathrm{~cm}$. However, diverse conditions should be taken into account when treating the absorption in He I line.
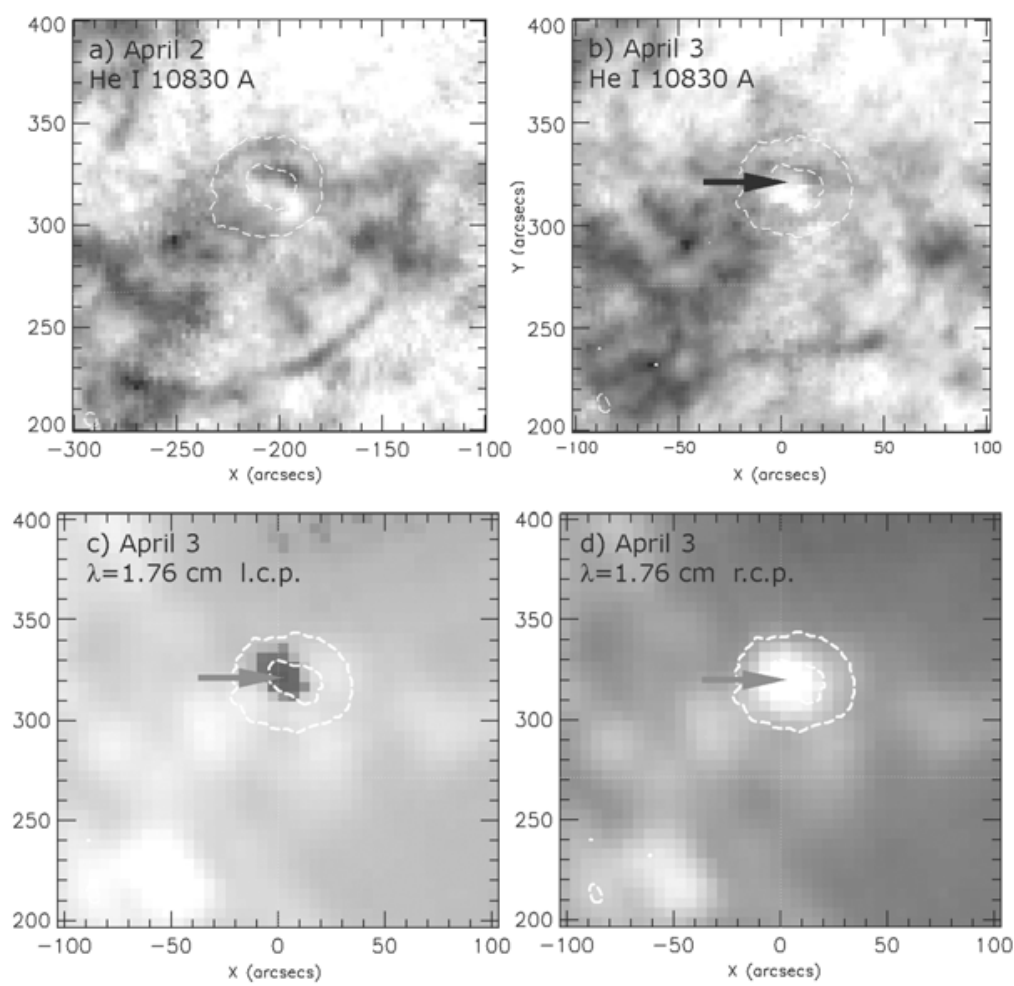

Fig. 5. Comparison of the intensity maps in chromospheric line He I $10830 \AA$ (the continuum of adjacent area is subtracted from the He I image of CHIP MLSO [10]) with the HoRH 1.c.p. and r.c.p. maps of microwave radiation at $\lambda=1.76 \mathrm{~cm}:(a) \mathrm{He} \mathrm{I}$ as of April 2; (b) He I as of April 3; (c) 1.c.p. at $1.76 \mathrm{~cm} ;(d)$ r.c.p. at $1.76 \mathrm{~cm}$. The sunspot umbra and penumbra of the sunspot on April 3 are displayed as dashed contours. Position of the minimum brightness in o-mode is marked by arrow.

Here we propose interpretation of some correlations between the listed above peculiarities in various wavelength ranges, which will be as follows. Two components of atmosphere (supposed to present two plasma flows in the opposite directions) coexist above the sunspot. The hot and somewhat rarefied plasma (pre- 
sumably in an upward flow) produces strongly polarized gyroresonance emission at short wavelengths. In turn, the cold plasma, which corresponds to the EUV sunspot plume mainly as a downward flow, does not produce appreciable microwave emission at these wavelengths. The correlation seems to be valid at least for the time interval near the central meridian passage (April 2-3).

We do not examine here the high day-to-day dynamics of the He I images in relation to the position of picks in the 1D microwave scans (see Fig. 3). Nevertheless, the overall timeline of the microwave source evolution seems to give evidence for some kind of stability of the sunspot atmosphere on a large scale.

\section{ACTIVE REGION 10325: MODEL RESULTS}

We will start with an axi-symmetric model of the sunspot atmosphere, which allows later correction for the apparent asymmetry both in the microwave and the EUV images. Thus modelled atmosphere should simulate the microwave emission from the sunspot-associated source NOAA 10325. The observed features taken into account are as follows.

- As the sunspot source is stable, the magnetic field of the sunspot is simulated by a dipole submerged to a constant depth of $3 \cdot 10^{9} \mathrm{~cm}$ below the photosphere level where $B_{\max }=3500$ Gauss.

- The axial symmetry of the modelled atmosphere is inferred from the time symmetry of the microwave features in o-mode relative to the time of CSM passage. Hence, a set of truncated conical surfaces is taken as a framework of the temperature-density structure to simulate the faster growth of radio brightness in o-mode at longitudes $|\theta|>50^{\circ}$ (with a minor temperature gradient along some ray paths).

- Low temperatures within the conical surfaces relative to the surrounding atmosphere are preferred when simulating a nearly constant size of the sunspot source (not changing within the wavelength range $2-6 \mathrm{~cm}$ ). If this is the case, the gyroresonance radiation from the "legs" of gyro levels is lowered.

- The low brightness temperature in o-mode (down to $T_{B}{ }^{o}=3100 \mathrm{~K}$ at longitudinal distances $|\theta|<50^{\circ}$ ) implies a low opacity in o-mode along a ray path until the level of the temperature minimum is reached. Hence, the modelled electron density along the ray path towards the depression in omode brightness should accordingly be decreased.

The main component of the modelled atmosphere above the large sunspot's umbra [12] is taken as a base for relevant modifications in the frame of the above observed features. Into the model a set of isothermal volumes within the coaxial truncated conical surfaces are incorporated. The four free model parameters are: a kinetic temperature factor, a plasma density factor within the conical areas, the height and the opening of cones. Due to the lack of resolution of radiotelescope RATAN-600 we were unable to search for a unique set of all the free parameters and, hence, to obtain a unique model solution; rather a hint of the solution type was sought for. Figure 6 presents the ultimate temperature and density distributions in the vertical section of the modelled atmosphere obtained with the model parameters on the condition that the convolutions (Fig. 7) fit the 1D radio scans (Fig. 3). 

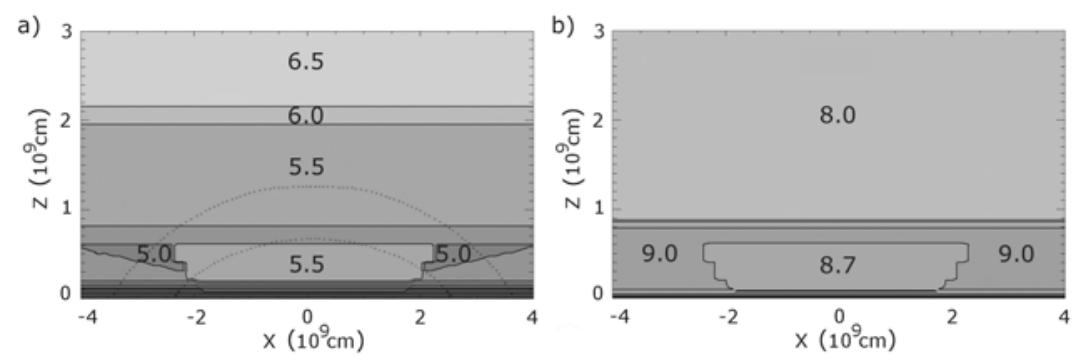

Fig. 6. Vertical section of the axially-symmetrical model of the sunspot NOAA 10325 atmosphere. The logarithms of electron temperature $(\mathrm{K})(a)$, and electron density $\left(\mathrm{cm}^{-3}\right)(b)$ are marked by contours. The dotted lines denote gyroresonance levels $s=2(B=2130 \mathrm{G})$ and $s=3(B=1420 \mathrm{G})$ for the wavelength $2.52 \mathrm{~cm}$.

To simulate the gyroresonance emission from the sunspot-associated source we applied the procedure described in [13]. The microwave images in o- and emodes are simulated at definite RATAN-600 wavelengths. Each 2D image is convoluted with the diagram pattern of the radio telescope RATAN-600 (Fig. 7).
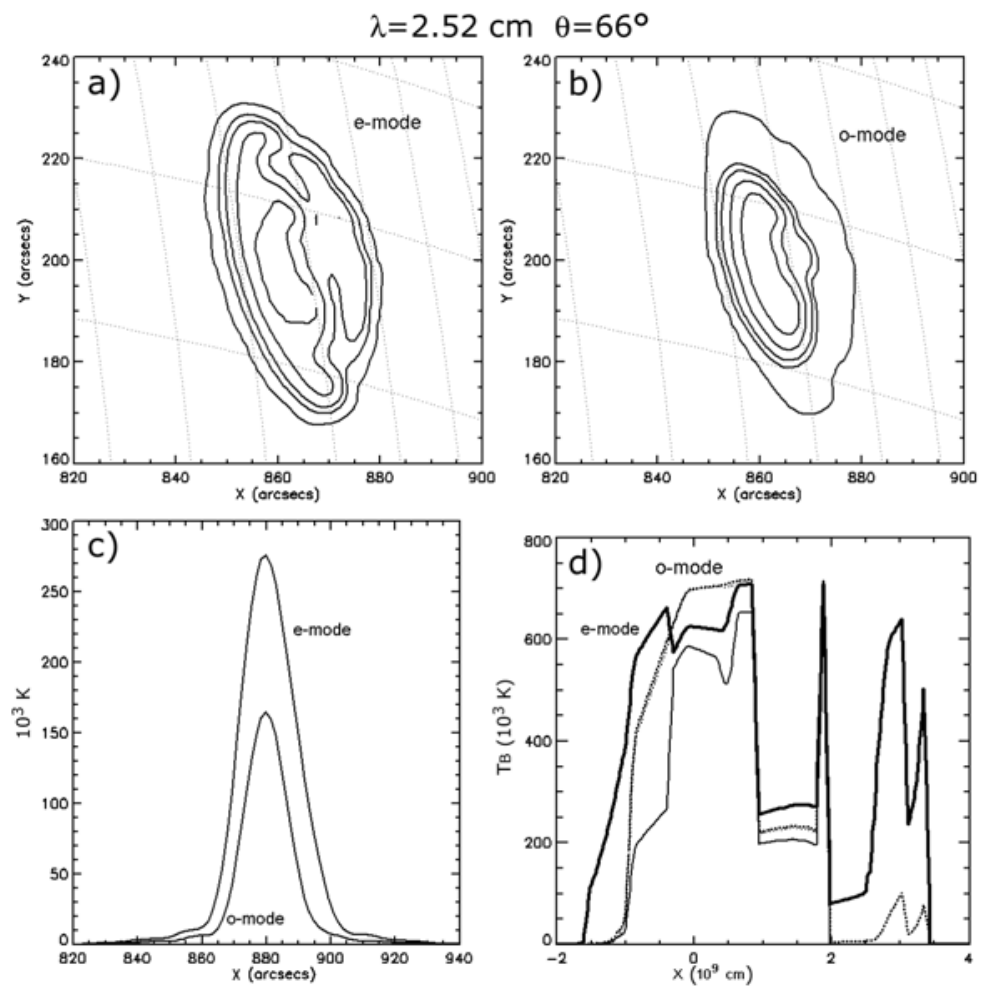

Fig. 7. Simulated gyroresonance emission at $2.52 \mathrm{~cm}$. The 2D images of radio brightness in e- $(a)$ and o- $(b)$ modes are exposed in the heliographic coordinates. The radio brightness contour levels are: 10 , $100,200,400,600 \times 10^{3} \mathrm{~K}$. (c) The 1D radio scan resulted from convolution of the model radio brightness with the RATAN-600 beam pattern at $2.52 \mathrm{~cm}$ (the $x$-axis refers to the RATAN-600 scanning direction with the angle of solar rotation axis $P=-6.3)$. (d) The simulated brightness temperature along the central section $Y=195$ " of the microwave source: in e-mode emission (thick line), with distinct contribution to e-mode brightness of $2^{\text {nd }}$ gyro level (solid line); in o-mode emission (thick dotted line) with distinct contribution to o-mode brightness of 2 gyro level (dotted line). 


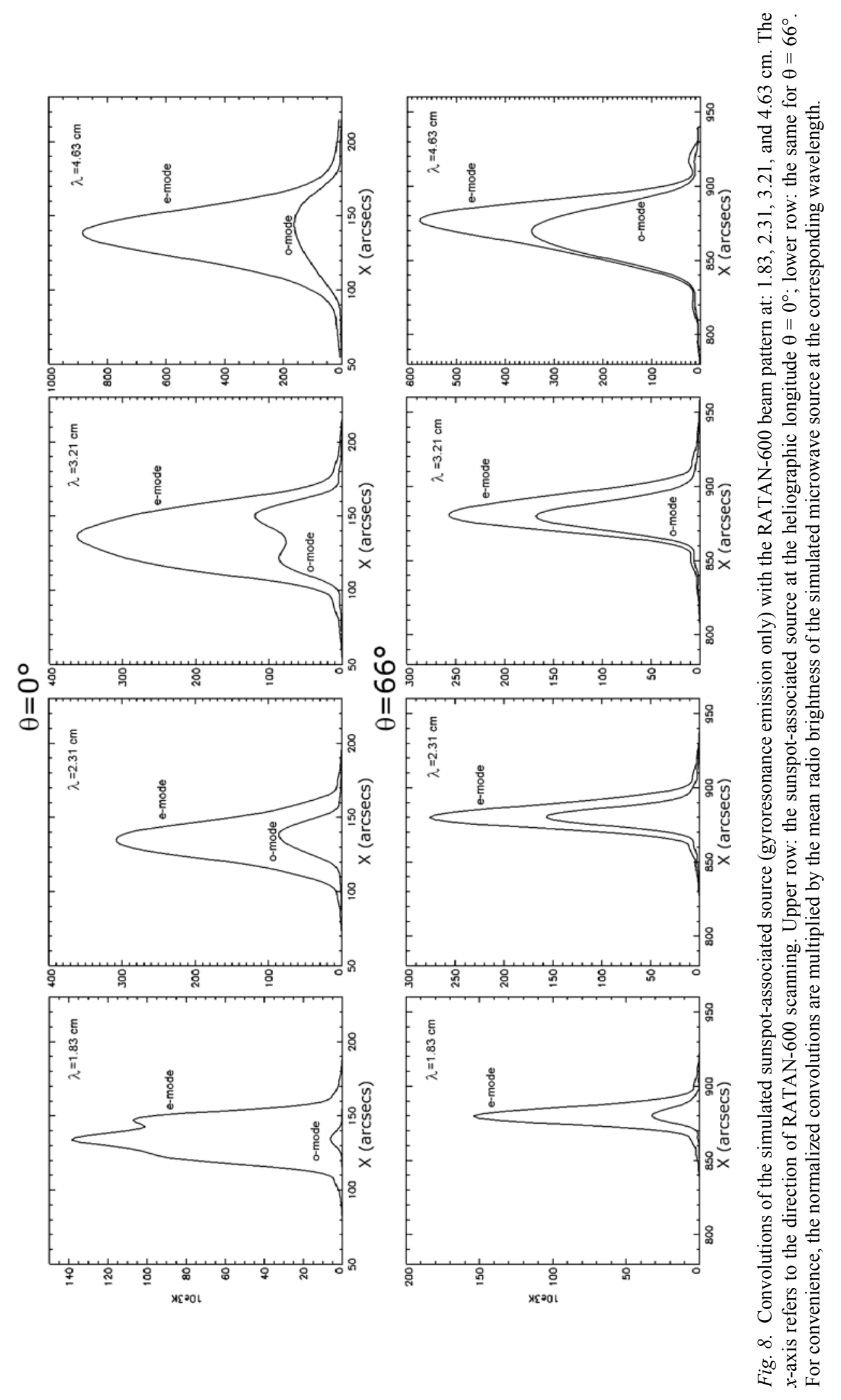


It may be deduced that some similarity in characteristic sizes, radio brightness and circular polarization (cf. Figs. 3 and 8, where the convolutions of the simulated source with a RATAN-600 beam pattern are shown) is achievable with the atmosphere model under consideration. It is instructive to analyze in detail the simulated microwave images in terms of the relative position of gyro levels and the temperature gradients. The model results for a set of the microwave source positions near the CSM are more or less straightforward. The more complicated for analysis is the position on the solar disk where the microwaves can come from the region at a gyroresonance level located in a cold plasma cone at the sunspot's periphery. In this case, the temperature gradient along the ray path could be negative, with the result of local o-mode prevalence in the radio brightness (Fig. 7d). The most important aspects of the model results are as follows.

1. With overestimated $B_{\max }=3500$ Gauss (Fig. 2) we found that the bulk of radiation in both normal modes comes from the $2^{\text {nd }}$ gyro level (the related wavelength range 2.3-3.6 cm). In fact, the SOHO MDI measurements have shown that the strength of the NOAA 10325 sunspot magnetic field might be close to the threshold of $3040 \mathrm{G}$ in order to keep the gyro level $s=2$ at $\lambda=1.76 \mathrm{~cm}$. To avoid the uncertainty with the $3^{\text {rd }}$ gyro level we use the overestimated value of $B_{\max }$, thus overestimating the availability of the $2^{\text {nd }}$ gyro level, especially at short wavelengths.

The closer the microwave source to the central solar meridian, the greater is the relative contribution of $s=2$. As for the $3^{\text {rd }}$ gyro level, its contribution to the radiation in o-mode increases with heliographic longitude: at short $(\lambda<1.8 \mathrm{~cm})$ and long $(\lambda>4.6 \mathrm{~cm})$ wavelengths this contribution exceeds $10 \%$ if $|\theta|>50^{\circ}$. The depression observed in the omode within the wavelength range $1.8-2.6 \mathrm{~cm}$ corresponds to the occurrence of the $2^{\text {nd }}$ gyro level in a relatively cold interlayer $\left(T \sim 10^{5.5} \mathrm{~K}, N \sim 10^{9} \mathrm{~cm}^{-3}\right)$ at a height $z \sim 710^{8} \mathrm{~cm}$. Along with low density at heights $z<710^{8} \mathrm{~cm}$, the modelled atmosphere is characterized by a wide transition region.

2. If we suggest existence of a low-lying region of $4000 \mathrm{~K}$ plasma, a low opacity is needed to detect this region at $\mathrm{cm}$ wavelengths near the solar disk centre $\left(|\theta|<50^{\circ}\right)$. This implies a rarefied plasma above the sunspot so that a layer with $N \sim 10^{10} \mathrm{~cm}^{-3}$ is negligible (its width is $\leq 10^{7} \mathrm{~cm}$ ) on the path. Here we suppose that the $4000 \mathrm{~K}$ cold plasma is associated rather with a region of the temperature minimum in the sunspot's atmosphere. If this is not the case and the cold plasma is associated with a "sunspot plume", the height of the region is less defined.

3. The angular size of the observed sunspot-associated source is nearly constant $\left(\approx 40^{\prime \prime}\right)$ in the $2-6 \mathrm{~cm}$ range. The simulated size of $30^{\prime \prime}-40^{\prime \prime}$ corresponds to the size of $2^{\text {nd }}$ gyro level. At $\lambda>5 \mathrm{~cm}$ the simulated size is limited by inclusion of the $10^{5} \mathrm{~K}$ cold plasma at the outer borders of the sunspot. The simulated spectrum of circular polarization is similar to the observed one, while the microwave source is close to the solar disk centre. At longitudes $|\theta| \sim 50^{\circ}$ the simulated c. p. spectrum shows two local maxima: $\approx 100 \%$ at $\lambda \approx 2 \mathrm{~cm}$ and $\approx 50 \%$ at $\lambda \approx 5 \mathrm{~cm}$ (the latter is observed at a shorter wavelength of $3.2 \mathrm{~cm}$ ). 
4. The simulated spectrum of radio brightness is in agreement with the observed one. In the accepted atmosphere model the steep increase of radio brightness in o-mode with longitude - as is clearly seen in Fig. 8 at $1.8-2.7 \mathrm{~cm}-$ results mostly from the increasing propagation angle and, partly, from the decreasing temperature gradient in the conical inclusions. The latter affects locally the brightness distribution across the microwave source. The most expressed contribution of conical inclusions to the o-mode radiation is on the microwave source side that is the closest to the solar limb border of the sunspot.

\section{DISCUSSION}

The microwave observations of the large stable sunspot NOAA 10325 are found to correlate with those of chromospheric He I absorption line and some EUV emission lines. The $1.8-2.7 \mathrm{~cm}$ wavelength coverage provides enough data to gain an impression about temperatures in the sunspot atmosphere based on simulation of the gyroresonance emission. The images taken in $\mathrm{He} \mathrm{I}$ absorption line and a number of EUV emission lines give a general idea about the structure of this atmosphere.

The absorption in He I $10830 \AA$ chromospheric line specifies the thermal structure in the range (1.0-2.5) $110^{4} \mathrm{~K}$ and the coronal EUV ionizing flux [14]. We consider the weak absorption in this line as the evidence of a low coronal density in the overlying coronal region producing a reduced ionizing flux.

The high-contrast feature ("sunspot plume") over the sunspot umbra is seen in some EUV emission lines. As mentioned in $\S 2.2$, the sunspot umbra is covered by plasma of the ion formation temperature $T_{m}=(2.2-4.5) 10^{5} \mathrm{~K}$. Both the maximum radio brightness in e-mode emission and its minimum in o-mode at $1.76 \mathrm{~cm}$ are shifted from the sunspot centre contrariwise to the EUV line emission (Fig. 4b). These extremes are located in the region of predominantly gyroresonance emission in e-mode, as the opacity of a gyro level depends much stronger on the propagation angle than in the case of thermal free-free emission $[1,2]$.

The proposed model of the sunspot atmosphere consists of two components at the levels of gyroresonance emission: (1) plasma at $T \approx 10^{5}-10^{6} \mathrm{~K}, N \approx 10^{9} \mathrm{~cm}^{-3}$, associated with "sunspot plumes" on the sunspot's periphery; and (2) plasma at $T \approx$ $10^{5.5}-10^{6} \mathrm{~K}, N \approx 10^{8} \mathrm{~cm}^{-3}$ associated with a low density region nearby the sunspot centre. If we take an overestimated value of the maximum strength of sunspot magnetic field in our simulations $\left(B_{\max }=3500 \mathrm{G}\right.$; Fig. 2), the transition region would be $\sim 10^{8} \mathrm{~cm}$ wide above the sunspot of NOAA 10325. Grebinskij et al. [15] have pointed out the extremely low coronal density above the sunspot umbra for isolated sunspots. The model is fitted to describe some particular features of the microwave emission (concurrent depression in o-mode and peak brightness in emode within the range $1.8-2.6 \mathrm{~cm}$ ) produced by gyroresonance mechanism. As can be inferred from the plume's structure, the first component of the modelled atomsphere is structurally loop-like. The second component is assumed to be located in a more open coronal structure of the magnetic field as evidenced by the trans- 
parency in o-mode of this component (low propagation angle) in the vicinity of CSM.

Although the proposed model of sunspot atmosphere does not describe precisely enough some features of the sunspot microwave emission, it points to the sought-for model type. Some microwave sources with sharp changes in o-mode and mainly associated with a large isolated sunspot are considered to be the case. The above comparison proves that there exist both the rarefied part of atmosphere and the region of low-temperature plasma with a steep temperature gradient. Unfortunately, we cannot base the axial symmetry of the cold inclusion on the angular resolution of the radio telescope RATAN-600.

\section{CONCLUSIONS}

Our interpretation of the peculiar features of radio brightness at the wavelengths $1.76-2.67 \mathrm{~cm}$ based on the proposed model of sunspot atmosphere is as follows.

The steep radio brightness increase in the ordinary wave mode at longitudes $|\theta| \geq 50^{\circ}$ is the result of increasing propagation angle and, partly, of decreasing temperature gradient on $2^{\text {nd }}$ and $3^{\text {rd }}$ gyro levels. The temperature gradient decreases along the ray paths going through the peripheral inclusions in the plane-parallel density and temperature distribution of the sunspot atmosphere. The depression in o-mode near the central solar meridian (down to $3100 \mathrm{~K}$ below the quiet Sun brightness of $10^{4} \mathrm{~K}$ at $1.76 \mathrm{~cm}$ ) is due to the low microwave opacity of rarefied plasma, $N \sim 10^{8} \mathrm{~cm}^{-3}$, and low propagation angles above the centre of the sunspot.

\section{REFERENCES}

1. Zlotnik, E.Ya. (1968). Soviet Astronomy, 12 (2), 245-253.

2. Zlotnik, E.Ya. (1968). Soviet Astronomy, 12 (3), 464-472.

3. Gelfreikh, G.B., \& Nefed'ev, V.P. (1975). Pisma v Astron. Zh., (1), 32 (in Russian)

4. Nindos, A., Kundu, M.R., White, S.M., Shibasaki, K., \& Gopalswamy, N. (2000). Astrophys. J., 130, 485-499.

5. Topchilo, N., Peterova, N., \& Borisevich, T. (2010). Astronomy Report, 54 (1), 69-85.

6. Brosius, J.W., \& White, S.M. (2004). Astrophys. J., 601, 546-558.

7. Gelfreikh, G.B., \& Lubyshev, B.I. (1979). Soviet Astronomy, 23, 316-322.

8. Strong, K.T., Alissandrakis, C.E., \& Kundu, M.R. (1984). Astrophys. J., 277, 865-873.

9. Shibasaki, K. (2001). Astrophys. J., 550, 1113-1118.

10. MacQueen, R.M., Blankner, J.G., Elmore, D.F., Lecinski, A.R., \& White, O.R. (1998). Solar Physics, 182, 97-105.

11. Brajša, J., Pohjolainen, S., Ruždjak, V., Sakurai, T., Urpo, S., Vršnak, R., \& Wohl, H. (1994). Solar Physics, 163, 79-91.

12. Obridko, V.N., \& Staude, J. (1988). Astron. Astrophys., 189, 232-242.

13. Gelfreikh, G.B., Peterova N.G., \& Ryabov, B.I. (1987). Solar Physics, 108, 89-97.

14. Mauas, P.J.D., Andretta, V., Falchi, A., Falciani, R., Teriaca, L., \& Cauzzi, G. (2005). Astrophys. J., 619, 604-612.

15. Grebinslij, A., Shibasaki, K., Zhang, H. (1998). Proceedings of the Nobeyama Symposium, Kiyosato, Japan, Oct. 27-30, NRO Report 479, 59-64. 


\section{STABILA SAULES PLANKUMA \\ AR STRAUJĀM PARASTĀS MIKROVIL,N̦U EMISIJAS MODAS \\ IZMAIN̦ĀM MODEĻA ANALİZE}

D. Bezrukovs, B. Rjabovs, N. Peterova, N. Topčilo

Kops av $1 \mathrm{kums}$

Darbā pirmoreiz ar skaitliska modeḷa palīdzību izanalizēti unikāli lokāla mikroviḷnu diapazona ar Saules plankumu saistīta avota, kurš ir tumšs viḷnu garuma diapazonā 1,76-2,67 cm, radio novērojumi. Dati iegūti ar Nobejamas Radio Heliografu un RATAN-600 radioteleskopu. Noskaidrots, ka avots ir tumšs parastajā modā un gaišs ekstraordinārajā modā tāpēc, ka mikroviļ̣ni šķērso atmosfēras slāni ar negatīvu temperatūras gradientu. Parādīts, ka modeļa aprēķinu ceļā iegūtie skaitliskie rezultāti sakrīt ar novērojumu datiem. Pamatojoties uz šiem novērojumiem un analīzēm, uzkonstruēts šim Saules plankumam jauns modelis, kas sastāv no divām dal̦ām: 1) ar "zemo" temperatūru $T \sim 10^{5}-10^{6} \mathrm{~K}$ un "augsto" blīvumu $N \sim 10^{9} \mathrm{~cm}^{-3}$ un 2) ar temperatūru $T \sim 10^{5.5}-10^{6} \mathrm{~K}$ un ,zemo" blìvumu $N \sim 10^{8} \mathrm{~cm}^{-3}$.

22.03.2011. 